\title{
Body weight status, eating behavior, sensitivity to reward/punishment, and gender: relationships and interdependencies
}

\section{Anja Dietrich ${ }^{*}{ }^{*}$, Martin Federbusch ${ }^{1,2}{ }^{+}$, Claudia Grellmann ${ }^{1,2}$, Arno Villringer ${ }^{1,2,3,4,5}$ and Annette Horstmann ${ }^{1,2,6}$}

${ }_{1}^{1}$ Department of Neurology, Max Planck Institute for Human Cognitive and Brain Sciences, Leipzig, Germany

${ }^{2}$ IFB Adiposity Diseases, Leipzig University Medical Center, Leipzig, Germany

${ }^{3}$ Clinic for Cognitive Neurology, University Hospital Leipzig, Leipzig, Germany

${ }^{4}$ Mind and Brain Institute, Berlin School of Mind and Brain, Humboldt-University and Charité, Berlin, Germany

${ }^{5}$ Collaborative Research Center 1052A1, University of Leipzig, Leipzig, Germany

${ }^{6}$ Collaborative Research Center 1052A5, University of Leipzig, Leipzig, Germany

\section{Edited by:}

Tanya Zilberter, Infotonic Conseil,

France

\section{Reviewed by:}

Caroline Davis, York University, Canada

Gilly Koritzky, University of Southern California, USA

\section{${ }^{*}$ Correspondence:}

Anja Dietrich, Department of Neurology, Max Planck Institute for Human Cognitive and Brain Sciences, Stephanstraße 1a, Leipzig 04103, Germany

e-mail:adietrich@cbs.mpg.de

${ }^{\dagger}$ Anja Dietrich and Martin Federbusch have contributed equally to this work.
Behavioral and personality characteristics are factors that may jointly regulate body weight. This study explored the relationship between body mass index (BMI) and selfreported behavioral and personality measures. These measures included eating behavior (based on the Three-Factor Eating Questionnaire; Stunkard and Messick, 1985), sensitivity to reward and punishment (based on the Behavioral Inhibition System/Behavioral Activation System (BIS/BAS) scales) (Carver and White, 1994) and self-reported impulsivity (based on the Barratt Impulsiveness Scale-11; Patton etal., 1995). We found an inverted U-shaped relationship between restrained eating and BMI. This relationship was moderated by the level of disinhibited eating. Independent of eating behavior, BIS and BAS responsiveness were associated with $\mathrm{BMI}$ in a gender-specific manner with negative relationships for men and positive relationships for women. Together, eating behavior and BIS/BAS responsiveness accounted for a substantial proportion of BMI variance (men: $\sim 25 \%$, women: $\sim 32 \%)$. A direct relationship between self-reported impulsivity and BMI was not observed. In summary, our results demonstrate a system of linear and non-linear relationships between the investigated factors and BMI. Moreover, body weight status was not only associated with eating behavior (cognitive restraint and disinhibition), but also with personality factors not inherently related to an eating context (BIS/BAS). Importantly, these relationships differ between men and women.

Keywords: eating behavior, gender differences, obesity, personality traits, reward sensitivity, punishment sensitivity, Behavioral Activation System, Behavioral Inhibition System

\section{INTRODUCTION}

Body weight regulation and the development of obesity are associated with multiple interdependent factors and mechanisms. These mechanisms include, at the individual level, genetic and endocrine factors as well as behavioral and personality characteristics (e.g., Williamson et al., 1995; Bellisle et al., 2004; Provencher etal., 2004; Dina et al., 2007; Farooqi et al., 2007; Frayling etal., 2007; Klok etal., 2007; Ahima, 2008; Davis and Fox, 2008; Rosenbaum etal., 2008; Page et al., 2011). One of the most important factors contributing to body weight status is eating behavior, which is commonly assessed by the ThreeFactor Eating Questionnaire (TFEQ; Stunkard and Messick, 1985). The TFEQ measures three dimensions of eating behavior: $\operatorname{cog}$ nitive restraint (CR), disinhibition (DIS), and susceptibility to hunger or hunger (HUN), for short. Cognitive restraint measures individual control over eating. Restrained eaters attempt to suppress impulses to eat in order to pursue long-term weight goals. Typical characteristics are avoidance of fattening foods and eating of small portions. The factor disinhibition reflects overeating tendencies. Disinhibited eaters typically initiate eating because of external environmental cues, such as palatable food. They have difficulties resisting food stimulation and/or eat under emotional distress. Considering this, cognitive restraint (conscious restriction of food intake) and disinhibition (tendency to overeat) conceptually represent antagonistic concepts. The third factor, hunger, characterizes the extent to which hunger feelings are experienced and evoke food intake. While hunger and disinhibition are positively associated with body mass index (BMI; e.g., Bond etal., 2001; Boschi etal., 2001; Bellisle etal., 2004; Bryant etal., 2008; Lesdéma etal., 2012), the relationship of cognitive restraint and BMI seems to be more complex and non-linear: In normal weight individuals they are usually positively associated, but the relationship is typically negative in overweight and obese individuals (e.g., Foster et al., 1998; Lluch etal., 2000; Bellisle etal., 2004; Provencher et al., 2004; de Lauzon-Guillain et al., 2006; Cappelleri et al., 2009). Additionally, cognitive restraint and disinhibition are not independently related to BMI, they interactively influence body weight 
status (Stunkard and Messick, 1985; Westenhoefer et al., 1990; Williamson etal., 1995; Hays etal., 2002; Dykes etal., 2004). Specifically, cognitive restraint attenuates the effect of disinhibition on BMI. What is more, previous investigations indicate that eating behavior (including presumably also underlying biological mechanisms) and body weight status mutually influence each other. For example, there are alterations in the level of cognitive restraint as well as disinhibition in response to dieting (e.g., Karlsson et al., 1994; Pekkarinen et al., 1996; Foster et al., 1998; Westerterp-Plantenga et al., 1998; Dalle Grave et al., 2009; Savage et al., 2009; Tucker and Bates, 2009).

In addition to eating behavior, various personality traits are related to food consumption and weight status (Faith et al., 2001; Elfhag and Morey, 2008). One of the most popular models of personality that may explain individual variations in food intake is the reinforcement sensitivity theory (RST; Gray, 1970, 1982, 1987; Gray and McNaughton, 2000). Based on this theory, two general motivational systems that underlie behavior and affect have been suggested-the Behavioral Inhibition System (BIS) and the Behavioral Activation System (BAS), commonly assessed by the BIS/BAS scales (Carver and White, 1994). The BIS represents the aversive motivational system. It is sensitive to signals of punishment, reward omission, and novelty. The BIS is supposed to inhibit behavior that may lead to negative or painful outcomes and is associated with negative affect (negative reinforcement). The BAS reflects the appetitive motivational system. It is sensitive to signals of reward and the avoidance of punishment (positive reinforcement). High BAS responsiveness is related to enhanced approach behavior and positive affect.

As food can be both a positive or negative reinforcer, responsiveness of these systems potentially plays a substantial role in body weight regulation. However, the relationship between sensitivity to reward (as a facet of BAS responsiveness) and BMI has been almost exclusively investigated in women. Investigations showed positive associations of reward sensitivity with BMI and eating habits supporting weight gain (Davis et al., 2004, 2007; Franken and Muris, 2005). In addition, reward responsiveness has been related to neural responses. In particular sensitivity to reward was shown to be positively associated with neural responses to pictures of highly palatable food in a fronto-striatalamygdala network (Beaver et al., 2006). Further findings indicate that long-lasting overeating and obesity account for adaptations of the reward system (Wang etal., 2001; Volkow etal., 2008; de Weijer etal., 2011). In combination with the aforementioned findings, these studies led to the development of a hyper-vs. hyposensitivity theory of reward in obesity (e.g., Davis and Fox, 2008). According to this theory, some individuals show an inherent heightened reward sensitivity (hypersensitivity) and are particularly susceptible to the rewarding properties of highcalorie food. They are thus supposed to regularly overeat on fattening food and consequently become overweight or obese. Prolonged overeating and corresponding obesity, on the other hand, are associated with alterations in the dopaminergic (DA) reward circuitry, presumably to compensate for an enhanced DA tone (Wang et al., 2001; Volkow et al., 2008; de Weijer et al., 2011). These alterations are assumed to result in hyposensitivity to reward in obese individuals as well as in increased hedonic eating to compensate this deficiency. This theory was explored by Davis and Fox (2008). According to their model, in both genders BMI and sensitivity to reward are non-linearly associated by an inverted U-shaped relationship. More specifically, the authors reported high reward sensitivity in overweight and mildly obese participants and low reward sensitivity in morbidly obese ones. Thus, although sensitivity to reward and sensitivity to punishment are assumed to be dispositional traits rather than transient states or symptoms (Wilksch and Wade, 2009), at least sensitivity to reward seems to be flexible to a certain extent.

To our knowledge, the association between sensitivity to punishment and BMI so far has not yet been studied directly, although several studies demonstrate a relationship between sensitivity to punishment and eating disorders. Similar to obese subjects, patients suffering from bulimia nervosa and anorexia nervosa (binge/purge subtype) are characterized by overeating. This points at possible similarities in the underlying personality structure leading to a shared decision-making profile (Brogan et al., 2010). Studies investigating eating disorders repeatedly report high punishment responsiveness in patients compared to healthy controls (e.g., Harrison et al., 2010, 2011). In addition, sensitivity to punishment has been shown to be positively associated with symptoms of binge eating (Davis, 2013). Again, these studies are almost exclusively restricted to women. Matton et al. (2013) clustered adolescents with respect to reward and punishment responsiveness. Interestingly, the cluster of subjects with both high reward sensitivity and high punishment sensitivity outscored other clusters on self-reported eating problems (i.e., data regarding concerns about eating, body shape and weight as well as emotional and external eating). Although girls were more likely to belong to this cluster, effects were similar for both girls and boys. Based on these findings, Matton et al. (2013) proposed that adolescents in this cluster are especially vulnerable to the development of eating problems.

Sensitivity to reward is regarded as one aspect of the multidimensional psychological construct impulsivity (e.g., Guerrieri et al., 2008). Generally, impulsive behavior is rapid and rash, characterized by a lack of planning and less forethought about consequences of spontaneous actions (Moeller et al., 2001). As the term "multidimensionality" indicates, impulsivity covers several different but related concepts. The relationship to overeating is thus not straightforward. While individual differences in some aspects of impulsivity are likely to contribute to the ability to resist overeating, others may not. Various tasks that assess aspects of impulsive behavior indicate altered decision-making in overweight and obese individuals. In Delay Discounting Tasks or Delay Gratification Paradigms, for example, obese subjects in general (Rasmussen etal., 2010) or obese women in particular (Weller et al., 2008; Weygandt et al., 2013) chose more often immediate but smaller monetary or food-related reward in comparison to normal weight control subjects. In the Iowa Gambling Task obese volunteers preferred high immediate reward despite long-term losses. This was shown in both genders (Pignatti et al., 2006; Brogan et al., 2011), women (Horstmann et al., 2011), or men (Koritzky et al., 2012). In addition, obese women and children of both genders 
lacked appropriate inhibitory control in the non-reward related Stop Signal Task (Nederkoorn et al., 2006a,b). Another task measuring inhibitory control, the Go/No-Go Task, showed especially overweight and obese adolescent girls to have difficulties inhibiting prepotent motor responses to high-calorie food (Batterink et al., 2010). Heightened impulsivity was also reported for overweight children (Braet et al., 2007) as well as overweight and obese adults (e.g., Chalmers et al., 1990; Mobbs et al., 2010) based on different self-reported measures. For example, Mobbs et al. (2010) reported higher levels of urgency, lack of perseverance and strong sensitivity to reward in overweight and obese women. They concluded that overweight and obesity are associated with problems in inhibiting dominant behavior and intrusive thoughts. Within the obese population, there is evidence for heightened self-reported impulsivity among severely compared to less severely obese individuals (Rydén et al., 2003), and impulsivity was further related to higher food intake in women using the Barratt Impulsiveness Scale (BIS; Guerrieri et al., 2007).

An important factor that contributes to differences in eating behavior and personality, and probably also to body weight regulation, is gender. Women, for example, have higher scores of cognitive restraint and disinhibition compared to men (Bellisle et al., 2004; Provencher etal., 2004; Li et al., 2012). Additionally, eating disorder symptomatology is more prevalent among women (e.g., Keel et al., 2007; Matton et al., 2013; Yean et al., 2013). Furthermore, men and women differ in personality traits such as impulsivity. For example, higher sensation seeking and behavioral risk taking was observed in men compared to women (Arnett, 1992; Byrnes et al., 1999; Cross et al., 2011). Additionally, both gender-independent and gender-specific effects have been reported, for example, with respect to the Iowa Gambling Task and weight status (Pignatti et al., 2006; Brogan et al., 2011; Horstmann et al., 2011; Koritzky et al., 2012). The precise relationship between impulsivity, BMI and gender thus is not clear from previous data. Furthermore, women are more sensitive to both reward and punishment compared to men (Carver and White, 1994; Jorm et al., 1999; Cross et al., 2011). Yet, the relationship of these measures to weight status has not been sufficiently explored in males, as described earlier. Differences in the hormonal repertoire between men and women might account for variations in the susceptibility to reinforcers like food. Ovarian hormones in particular, which affect mesolimbic DA system (i.e., reward processing; Sofuoglu et al., 1999; Kaasinen et al., 2001; Evans et al., 2002; Lynch et al., 2002; Carroll et al., 2004) but also HPA functioning (i.e., stress response; Burgess and Handa, 1992; Handa et al., 1994; Patchev et al., 1995; Young, 1995), might be responsible for such differences, making women generally more vulnerable to the reinforcing properties of most drugs of abuse (see Fattore et al., 2008, 2009 for review). As addiction and obesity share several properties (see Volkow et al., 2013 for review), there might be also gender differences in the susceptibility to the reinforcing value of food. For other personality domains and their association with weight status, the gender interaction has already been shown. In a study by Faith et al. (2001) BMI was positively associated with neuroticism and negatively with extraversion in women. In men, BMI was positively associated with extraversion and psychoticism (Faith et al., 2001). Finally, gender moderates obesity-related differences in brain structure. Specifically for women obesity-related variation were observed in regions involved in habitual and goal-directed control of behavior such as the dorsal striatum and dorsolateral prefrontal cortex (Horstmann et al., 2011).

Therapeutic approaches to obesity classically target aspects of eating behavior. Behavioral interventions, for example, aim at increasing cognitive restraint and decreasing disinhibition (e.g., Jubbin and Rajesh, 2012). Yet, as described above, individual body weight status is also related to personality traits. For a more effective treatment of obesity it is therefore necessary to regard personality traits as well. This study aims to establish a comprehensive model relating BMI to eating behavior and the most relevant obesity-related personality traits (self-reported impulsivity and reward/punishment sensitivity). We investigated questionnaire measures of these traits as they can be easily and quickly assessed in the clinical setting. TFEQ scales cognitive restraint, disinhibition, and hunger (Stunkard and Messick, 1985) served as measures of eating behavior. The BIS/BAS scales (Carver and White, 1994) were considered as measures of sensitivity to punishment (BIS) and sensitivity to reward (BAS). Further, self-reported impulsivity, assessed by the BIS-11 (Patton et al., 1995), was incorporated into the model. The overall goal of our approach was to quantify the individual and joint contribution of these scales to BMI variance explanation.

Based on previous findings, different models were developed to test the following hypotheses:

(1) A significant proportion of BMI variance is explained by disinhibition, hunger, and cognitive restraint. According to previous findings, we assumed positive linear associations of both disinhibition and hunger with BMI (e.g., Bond et al., 2001; Boschi et al., 2001; Bellisle et al., 2004; Bryant et al., 2008; Lesdéma et al., 2012). As cognitive restraint and BMI are positively associated in normal weight individuals and negatively in overweight and obese individuals (e.g., Foster et al., 1998; Lluch et al., 2000; Bellisle et al., 2004; Provencher et al., 2004; de Lauzon-Guillain et al., 2006; Cappelleri et al., 2009), we expected an inverted U-shaped relationship between these variables.

(2) A portion of BMI variance is explained by the interaction of disinhibition and cognitive restraint, indicated by previous studies (Stunkard and Messick, 1985; Westenhoefer et al., 1990; Williamson et al., 1995; Hays et al., 2002; Dykes et al., 2004).

(3) Additional BMI variance is explained by the level of BIS (as a measure of punishment responsiveness) and BAS (as a measure of reward responsiveness). Based on previous research, we expected positive linear associations for both variables with BMI in women (Davis et al., 2004, 2007; Franken and Muris, 2005; Harrison et al., 2010, 2011). Despite the lack of previous data for these relationships in men, we expect the positive relationships between BIS/BAS and BMI to be specific for women, which is based on gender-dependent differences in the hormonal repertoire influencing the vulnerability to reinforcers (e.g., Sofuoglu et al., 1999; Kaasinen et al., 2001; Evans et al., 2002; Lynch et al., 2002; Carroll et al., 2004). 
(4) Further, BMI variance is explained by the level of self-reported impulsivity (BIS-11). According to previous findings, we expected a positive linear association with BMI (e.g., Chalmers et al., 1990; Rydén et al., 2003; Mobbs et al., 2010). Considering opposing findings with respect to gender (Pignatti et al., 2006; Brogan etal., 2011; Horstmann et al., 2011; Koritzky et al., 2012), we tested for gender interactions, although they were not expected.

Besides the study's main purpose of modeling BMI, we had two secondary objectives:

(5) Cognitive restraint, disinhibition, and body weight status mutually influence each other (e.g., Karlsson et al., 1994; Pekkarinen etal., 1996; Foster etal., 1998; Westerterp-Plantenga et al., 1998; Dalle Grave et al., 2009; Savage et al., 2009; Tucker and Bates, 2009). Therefore, we hypothesized the quadratic relationship between BMI and cognitive restraint to be moderated by disinhibition. Depending on the level of disinhibition, we expected the association of BMI and cognitive restraint to be as follows: Normal body weight and low disinhibition is associated with low cognitive restraint. Normal body weight and high disinhibition is associated with high cognitive restraint. Overweight is associated with high cognitive restraint regardless of the level of disinhibition. Obesity is associated with low cognitive restraint regardless of the level of disinhibition.

(6) Davis and Fox (2008) demonstrated an inverted U-shaped relationship between sensitivity to reward and BMI. We aimed to corroborate these findings by testing for a quadratic relationship between $B A S$ and BMI. We hypothesized an inverted $\mathrm{U}$-shaped relationship between these measures.

As the focus of this investigation was on self-report questionnaires, i.e., explicit, mentally represented data, this study did not consider implicit or automatic processes (i.e., eating habits) that influence behavior and potentially body weight independently of explicit experience (e.g., Berridge and Robinson, 2003; Finlayson et al., 2008; Papies et al., 2009; Goldstein et al., 2014).

\section{MATERIALS AND METHODS SUBJECTS}

Data were collected by the joint obesity work group of the Max Planck Institute for Human Cognitive and Brain Sciences and the IFB Adiposity Diseases in Leipzig between 2009 and 2013. Healthy adult subjects were invited to participate in different behavioral and neurocognitive experiments in the context of obesity research and were reimbursed for their participation. As part of these experiments, subjects completed various questionnaires this cross-sectional study is based on. Exclusion criteria were age under 18 or over 50 years, BMI under $18 \mathrm{~kg} / \mathrm{m}^{2}$, hypertension, dyslipidemia, metabolic syndrome, depression (Beck's Depression Inventory, cut-off value 18), a history of neuropsychiatric diseases, smoking, diabetes mellitus, vegetarianism, and pregnancy. Although there were no restrictions for ethnicity, only Caucasian subjects volunteered. Age in years and BMI were assessed at the time of the experiment. Height and weight for BMI calculations were measured by scientific staff at the Max Planck Institute in Leipzig. As not all questionnaires
Table 1 | Descriptive statistics.

\begin{tabular}{llllll}
\hline Variable & $\boldsymbol{n}$ & Mean (SD) & Range & $\begin{array}{l}\text { Mean } \\
\text { women (SD) }\end{array}$ & $\begin{array}{l}\text { Mean } \\
\text { men (SD) }\end{array}$ \\
\hline BMI & 326 & $26.6(6.1)$ & $18.1-46.5$ & $26.4(6.6)$ & $26.7(5.6)$ \\
& 192 & $26.7(6.2)$ & $18.1-46.5$ & $26.6(6.5)$ & $26.8(6.0)$ \\
Age & 326 & $26.7(4.8)$ & $18-46$ & $26.3(4.8)$ & $27.0(4.9)$ \\
& 192 & $26.6(4.7)$ & $18-46$ & $25.7(4.1)$ & $27.2(5.0)$ \\
CR & 326 & $6.5(4.6)$ & $0-19$ & $7.3(5.0)$ & $5.8(4.1)$ \\
& 192 & $6.7(4.7)$ & $0-19$ & $7.4(5.0)$ & $6.2(4.4)$ \\
DIS & 326 & $6.1(3.2)$ & $0-15$ & $6.8(3.5)$ & $5.6(2.8)$ \\
& 192 & $6.1(3.0)$ & $1-14$ & $6.8(3.3)$ & $5.6(2.6)$ \\
HUN & 326 & $5.5(3.3)$ & $0-14$ & $5.6(3.3)$ & $5.5(3.3)$ \\
BAS & 192 & $5.6(3.3)$ & $0-14$ & $5.9(3.4)$ & $5.4(3.3)$ \\
BIS & 192 & $30.9(8.8)$ & $13-51$ & $29.7(8.5)$ & $31.8(9.0)$ \\
BIS-11 & 192 & $17.0(3.9)$ & $5-26$ & $16.5(4.3)$ & $17.4(3.4)$ \\
\hline
\end{tabular}

Descriptive statistics of variables assessed in the TFEQ-only cohort $(n=326$, 145 women, 181 men) and the TFEQ-plus cohort (subgroup of TFEQ-only cohort (grey), $n=192,82$ women, 110 men). CR, TFEQ cognitive restraint score; DIS, TFEQ disinhibition score; HUN, TFEQ hunger score; BIS-11, Barratt Impulsiveness Scale 11 total score; BAS, Behavioral Activation System total score; BIS, Behavioral Inhibition System total score; TFEQ, Three-Factor Eating Questionnaire.

were assessed for all participants, we decided to investigate two cohorts (called TFEQ-only and TFEQ-plus cohort). The total cohort consisted of 326 healthy subjects (TFEQ-only cohort; 145 women, $181 \mathrm{men})$. Besides BMI, age, and gender, the TFEQ scores of $C R, D I S$, and $H U N$ were assessed in these subjects. In a subgroup of 192 participants, BIS, BAS, and BIS-11 were additionally assessed (TFEQ-plus cohort; 92 women, 110 men). Table 1 depicts descriptive statistics of the two cohorts. The study was carried out in accordance with the Declaration of Helsinki and approved by the local ethics committee of the University of Leipzig. All subjects gave written informed consent before participation.

\section{QUESTIONNAIRES}

\section{Three-Factor Eating Questionnaire (Stunkard and Messick, 1985;} German version: Pudel and Westenhoefer, 1989)

The TFEQ is a 51-item self-report assessment of eating behavior. The questionnaire contains three subscales. The 21-item cognitive restraint scale (CR, scale range: $0-21$, Cronbachs Alpha of German version $=0.84$ ) measures intent to control food intake. The 16item disinhibition scale (DIS, scale range: $0-16$, Cronbachs Alpha of German version $=0.75$ ) quantifies overeating tendencies. The 14-item susceptibility to hunger scale (HUN, scale range: 0-14, Cronbachs Alpha of German version $=0.76$ ) is a measure for food intake in response to feelings of hunger.

\section{The Behavioral Inhibition System/Behavioral Activation System Scales (Carver and White, 1994; German version: Strobel et al., 2001)} This self-report questionnaire consists of 20 items designed to assess the responsiveness of Gray's $(1982,1987)$ BAS and BIS as 
personality characteristics. The 7-item BIS scale measures reactivity of the aversive motivational system (scale range: 7-28, Cronbachs Alpha of German version = 0.78), whereas the 13item $B A S$ scale measures reactivity of the appetitive motivational system (scale range: 13-52, Cronbachs Alpha of German version $=0.81)$. The BAS scale can be divided into three subscales: Drive, Fun-Seeking, and Reward. In this study we applied the BAS sum score, as the subscales were not confirmed in the German version.

\section{Barratt Impulsiveness Scale-11 (Patton et al., 1995; German version:} Preuss et al., 2008)

The BIS-11 is a 30 -item self-report questionnaire developed to measure impulsivity. Along a four-point scale subjects rate whether statements describing impulsivity pertain to themselves (scale range: 0-90, Cronbachs Alpha of German version =0.69). For the original English version, six factors were identified. This originally suggested factor structure was not confirmed for the German equivalent. We therefore applied the total score of the BIS11 , as it shows adequate internal consistency for German-speaking regions.

\section{STATISTICAL ANALYSES}

Statistical analyses were performed using SPSS (IBM Corporation Released 2011. IBM SPSS Statistics for Windows, Version 20.0. Armonk, NY: IBM Corporation) and the SPSS toolbox PROCESS (Hayes, 2013). Associations between BMI and selfreported behavioral data were explored by means of multiple regression analyses. All variables except gender were treated as continuous variables. We separately tested for the association between the three TFEQ scales and BMI in the TFEQ-only cohort (see Association of the TFEQ Scales with BMI). Age and gender were included as covariates. Significant terms were subsequently used to build a regression model for BMI to assess the proportion of variance solely explained by variables of eating behavior (see BMI Modeling Based on the TFEQ Scales Cognitive Restraint and Disinhibition). Next, we tested BIS-11, $B I S$, and BAS seperately for their association with BMI in the TFEQ-plus cohort (see Association of the Barratt Impulsiveness Scale-11, Behavioral Activation System, and Behavioral Inhibition System Scales with BMI). Additionally, gender interactions for the relationships of the latter three scores with BMI were tested. Age and gender were included as covariates. Again, all significant terms were used to build a comprehensive regression model for BMI including eating behavior and personality traits (see BMI Modeling Based on Cognitive Restraint, Disinhibition, the Behavioral Activation System, and Behavioral Inhibition System Score).

Based on findings of previous studies, quadratic relationships between BMI and CR (moderated by DIS, see Interactions between Cognitive Restraint, Disinhibition, and BMI) and between BMI and BAS (see Quadratic Relationship between BMI and the Behavioral Activation System Score) were tested (Foster et al., 1998; Lluch etal., 2000; Bellisle etal., 2004; Provencher et al., 2004; de Lauzon-Guillain etal., 2006; Davis and Fox, 2008; Cappelleri et al., 2009). BMI was treated as regressor for these analyses.
Table 2 | Regression models and corresponding variables.

\begin{tabular}{|c|c|c|}
\hline $\begin{array}{l}\text { Association with } \\
\text { regressand }\end{array}$ & $\begin{array}{l}\text { Variables in } \\
\text { model }\end{array}$ & $\begin{array}{l}\text { Tested gender } \\
\text { interaction }\end{array}$ \\
\hline Linear & $\underline{A}, g, a$ & $\underline{A * g}$ \\
\hline Quadratic (e.g., $C R^{2}$ ) & $A, \underline{A^{2}}, g, a$ & $\underline{A^{2 *} g}$ \\
\hline $\begin{array}{l}\text { 2-way interaction } \\
\text { (DIS*CR) }\end{array}$ & $A, B, \underline{A^{*} B}, g, a$ & - \\
\hline $\begin{array}{l}\text { Quadratic 2-way } \\
\text { interaction }\left(\mathrm{BMI}{ }^{2 *} \mathrm{DIS}\right)\end{array}$ & $\begin{array}{l}A, B, A^{2}, A * B, \\
A^{2 *} B, g, a\end{array}$ & - \\
\hline
\end{tabular}

Different regression models were computed to test our individual hypotheses. Corresponding variables of all the investigated models are listed. Partial correlations of the underlined terms were tested against 0 . A, B: tested variables, e.g., Three-Factor Eating Questionnaire cognitive restraint (CR) or disinhibition score (DIS); g, gender; a, age.

Table 2 lists the regression models which were used to test all abovementioned associations. As measures of effect size we used partial correlations and squared partial correlations. The latter can be interpreted as the regressand's (e.g., BMI) proportion of variance which can be explained by a single regressor (e.g., DIS) when all other variables are held constant. For reasons of consistency, not to indicate causality, BMI was depicted at the $\mathrm{x}$-axis of every graph. We added a table of Pearson Correlations of the assessed variables at the end of the results section (see Pearson Correlations of All Variables of Interest).

\section{RESULTS}

TFEQ-ONLY COHORT ( $n=326$ )

Association of the Three-Factor Eating Questionnaire scales with BMI

In the total cohort of 326 subjects, a gender difference in $C R$ ( $p=0.004)$ and in DIS $(p=0.001)$ was observed, with women having higher scores in both cases. BMI significantly correlated with DIS, $C R^{2}$ (hypothesis 1), and the interaction term of $C R$ and DIS (hypothesis 2; Figure 1; partial correlations, all $p<0.0005$; see Table 3 ). We observed no significant association of $H U N$ with BMI.

\section{BMI modeling based on the TFEQ scales cognitive restraint and disinhibition}

To obtain a model for BMI regressed on the TFEQ scales, a multiple regression analysis using all former significant terms (i.e., $C R$, $D I S, C R^{2}$, and $C R^{*} D I S$; additional covariates age and gender) was conducted. The underlying adjusted $R^{2}$ of this model was 0.232 (women: 0.247 , men: 0.208 ). $C R^{*} D I S$ as well as $C R^{2}$ separately explained part of BMI variance, as their partial correlations differed from 0 (both $p<0.0005$ ). Hence, the TFEQ scales $C R$ and $D I S$ (in addition to age and gender) explained about $23 \%$ of the overall variance of BMI in the population of this cohort.

\section{Interactions between cognitive restraint, disinhibition, and BMI}

We hypothesized a quadratic relationship between $C R$ and BMI (hypothesis 5). The regression of $C R$ on $B M I^{2}$ confirmed this hypothesis (squared partial correlation: 0.029, $p=0.002$, age and gender as covariates). Furthermore, this inverted U-shaped 


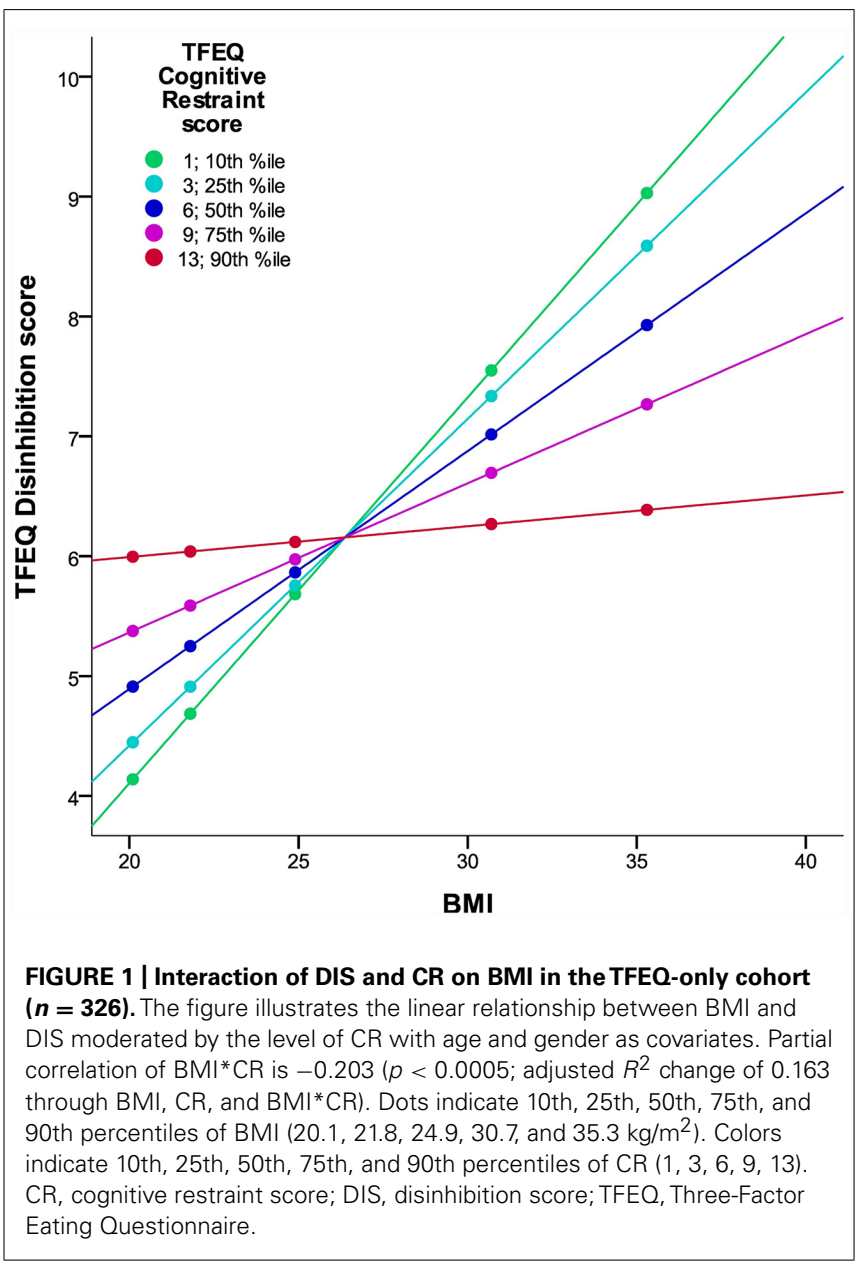

relationship was moderated by DIS $(p=0.001)$. In other words, the relationship between BMI and $C R$ differed with respect to the DIS score (Figure 2): For low DIS scores the quadratic association between $C R$ and BMI was well pronounced, whereas no strong quadratic relationship for high DIS scores was observed.

\section{TFEO-PLUS COHORT ( $n=192)$}

\section{Association of the Barratt Impulsiveness Scale-11, Behavioral Activation System, and Behavioral Inhibition System Scales with BMI}

With respect to eating behavior (based on the TFEQ), results in the subgroup of 192 participants (TFEQ-plus cohort) were comparable with the whole sample (TFEQ-only cohort, $n=326)$.

$B A S$ and BIS scores did not correlate with BMI, but showed a significant interaction with gender (hypothesis 3 ; all $p=0.001$ ). In women, there was a significant positive correlation of BIS and BMI (partial correlation $=0.281 ; p=0.011$ ) as well as a strong tendency for the correlation of BAS and BMI (partial correlation $=0.214 ; p=0.055)$. In men, we found a significant negative correlation of $B I S$ and $B M I$ ( partial correlation $=-0.208$; $p=0.03$ ) as well as BAS and BMI (partial correlation $=-0.295$; $p=0.002)$. The relationship of BMI and BAS, moderated by
Table 3 | Squared partial correlations (SPC) with BMI.

\begin{tabular}{lllc}
\hline Variable & $\begin{array}{l}\text { Squared partial } \\
\text { correlation }\left(\eta_{\mathbf{p}}^{\mathbf{2}}\right)\end{array}$ & $\begin{array}{l}\text { Direction of } \\
\text { correlation }\end{array}$ & $\boldsymbol{p}$-value \\
\hline $\mathrm{CR}$ & $(0.009)$ & $(+)$ & 0.083 \\
$\mathrm{DIS}$ & 0.138 & + & $<0.0005$ \\
$\mathrm{HUN}$ & $(0.003)$ & $(+)$ & 0.596 \\
$\mathrm{CR}^{2}$ & 0.054 & - & $<0.0005$ \\
$\mathrm{CR}^{*}$ DIS & 0.054 & - & $<0.0005$
\end{tabular}

Squared partial correlations with BMI in the TFEQ-only cohort $(n=326)$ in a regression model with age and gender as covariates. SPC can be interpreted as the proportion of $B M I$ variance explained only by the corresponding variable, not by covariables. CR, TFEQ cognitive restraint score; DIS, TFEQ disinhibition score; HUN, TFEQ hunger score; TFEQ, Three-Factor Eating Questionnaire.

gender, is shown in Figure 3 (results for the association of BIS and BMI are comparable). Concerning the association of selfreported impulsivity and BMI, neither a correlation between BMI and BIS-11 (total score) nor a gender interaction was found (hypothesis 4).

\section{BMI modeling based on cognitive restraint, disinhibition, the Behavioral Activation System, and Behavioral Inhibition System score}

The final model comprised the relevant variables of self-reported eating behavior (see BMI Modeling based on the TFEQ Scales Cognitive Restraint and Disinhibition, TFEQ-only model) as well as $B I S, B A S$, gender, $B I S^{*}$ gender, $B A S^{*}$ gender and age as regressors. The resulting adjusted $R^{2}$ was 0.271 (women: 0.324 , men: 0.252 ). $R^{2}$ for women and men did not differ significantly $(p=0.474$, two-tailed Fisher's Z). Independent of eating behavior, BIS and $B A S$ significantly contributed to variance explanation of BMI $\left(R^{2}\right.$ change of TFEQ-only model and TFEQ-plus model in the sample of $n=192, p<0.0005)$. Hence, self-reported behavioral measures of $C R, D I S, B I S$, and $B A S$ in addition to age and gender explained about $27 \%$ of the overall variance of BMI in the population of this sample. See Figure 4 for variance proportions of the variables for each gender.

\section{Quadratic relationship between BMI and the Behavioral Activation System score}

As Davis and Fox (2008) reported an inverted U-shaped association between sensitivity to reward and BMI, we tested for the quadratic association of BAS with BMI (hypothesis 6). We corroborated their finding: BMI showed a quadratic relationship with $B A S$ ( $p=0.018$, age and gender as covariates, adjusted $R^{2}$ changed by 0.03 after adding $\mathrm{BMI}$ and $\mathrm{BMI}^{2}$ ). There was only a trend for a gender interaction of this effect $(p=0.091$, stronger effect in women). Concerning the model, a BMI of around $30 \mathrm{~kg} / \mathrm{m}^{2}$ was associated with the highest BAS scores, whereas a higher and lower BMI was associated with lower BAS scores (Figure 5).

\section{PEARSON CORRELATIONS OF ALL VARIABLES OF INTEREST}

For an overview of the assessed variables and how they are interrelated, see Table 4. As the correlation of BIS and BAS was not 


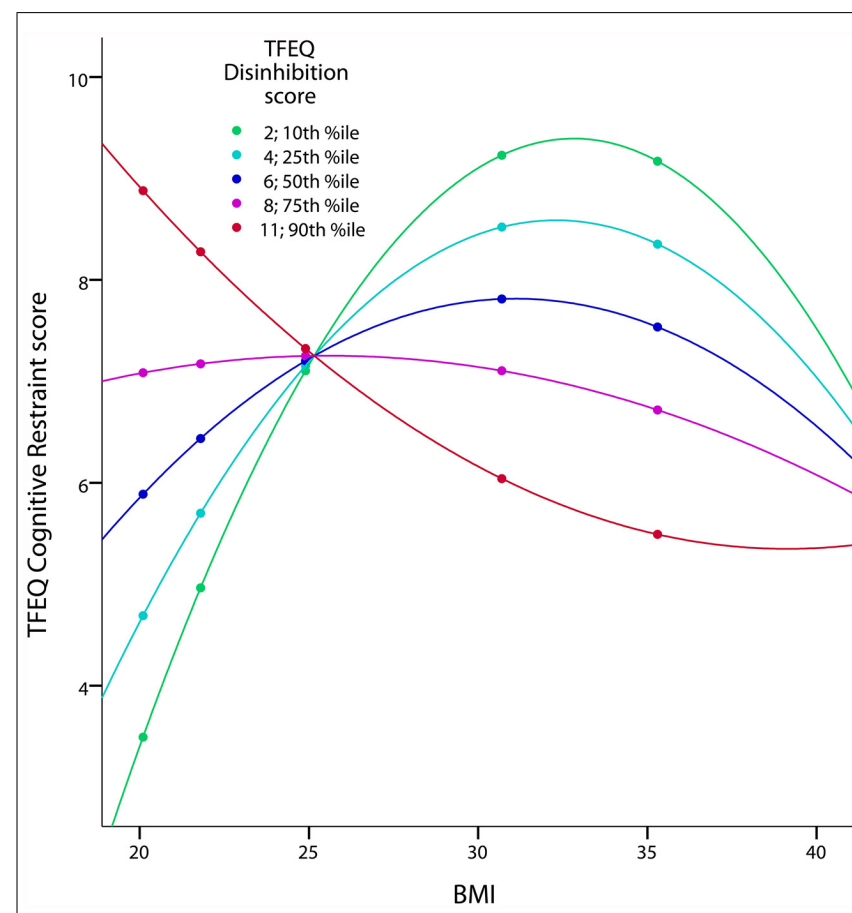

FIGURE 2 | Quadratic interaction of BMI and DIS on CR in the TFEQ-only cohort $(\boldsymbol{n}=\mathbf{3 2 6})$. The figure illustrates the quadratic relationship between BMI and CR moderated by the level of DIS with age and gender as covariates. Partial correlation of $\mathrm{BMI}^{2}{ }^{*} \mathrm{DIS}$ is 0.185 ( $p<0.001$; adjusted $R^{2}$ change of 0.083 through BMI, DIS, BMI ${ }^{2}, \mathrm{BMI}{ }^{*}$ DIS

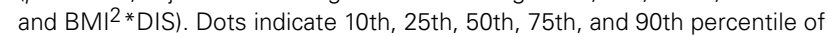
BMI $\left(20.1,21.8,24.9,30.7\right.$, and $\left.35.3 \mathrm{~kg} / \mathrm{m}^{2}\right)$. Colors indicate 10 th, 25th, 50 th, 75th, and 90th percentiles of $\operatorname{CR}(2,4,6,8,10)$. CR, cognitive restraint score; DIS, disinhibition score; TFEQ, Three-Factor Eating Questionnaire.

described thus far, this association was further investigated. One reason for this relationship might be the high proportion of obese subjects in our sample. Therefore we tested for an interaction of BMI with BIS or BAS. Also gender interactions of this assumed effects were tested. We found a 3-way-interaction between BMI, gender and $B I S\left(p=0.007\right.$ for $B I S^{*} \mathrm{BMI}^{*}$ gender with $B A S$ as regressand; age as covariate). Probing this 3-way-interaction revealed that women with a high BMI had a stronger association of BIS with $B A S$.

\section{DISCUSSION}

\section{RELATIONSHIP BETWEEN EATING BEHAVIOR AND BMI}

Interestingly, only two measures of eating behavior, disinhibition and cognitive restraint, accounted for much of BMI variance ( $\sim 23 \%)$. In other words, the individual level of overeating tendencies in interaction with the level of conscious efforts to restrict food intake explained a large amount of variance in individual body weight status. Susceptibility to hunger did not contribute to variance explanation of BMI. However, an association of hunger with disinhibition and cognitive restraint was shown in our sample, which is in line with previous studies (Bellisle et al., 2004; Lesdéma et al., 2012).

Besides modeling of BMI, we aimed to investigate the apparent non-linear relationship between cognitive restraint and BMI.

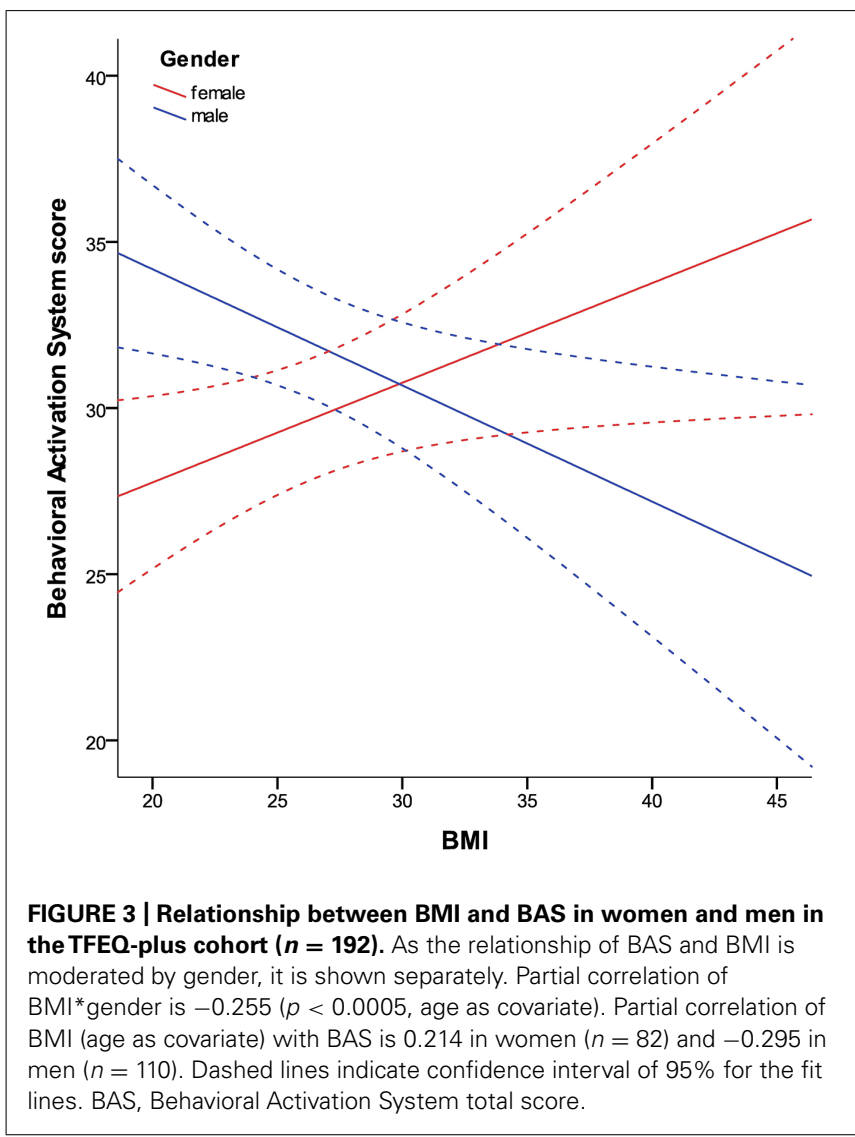

We found an inverted U-shaped association of BMI with cognitive restraint. Our model demonstrates low levels of cognitive restraint at the outer edges of the BMI range and a high level around the overweight range. Interestingly, this relationship was moderated by the level of disinhibition. For low levels of disinhibition (low overeating tendencies) the curvilinear relationship between BMI and cognitive restraint was well pronounced. Accordingly, we conclude that restrained eating is low in normal weight individuals as food restriction is presumably not necessary. With higher BMI, food restriction becomes necessary, as losing weight or avoiding further weight gain are supposedly more frequent with higher BMI (maximum in the overweight/moderate obese range of the $\mathrm{BMI}$ ). In the obese $\mathrm{BMI}$ range, the positive relationship between BMI and cognitive restraint is shifted, resulting in relatively low levels of restrained eating among morbidly obese individuals. Although restrained eating seems desirable in this BMI range, morbidly obese individuals might not be able to raise sufficient self-control resources to restrict food intake. This notion is supported by neuroimaging studies that report structural as well as functional obesity-related alterations in brain structures associated with self-control (Le et al., 2006, 2007; Horstmann et al., 2011). With higher levels of disinhibition there was no strong curvilinear relationship between $\mathrm{BMI}$ and cognitive restraint. This effect indicates that in response to heightened overeating tendencies, normal weight individuals increase conscious efforts to restrict food intake in order to maintain weight/stay slim. Overweight and moderately obese 


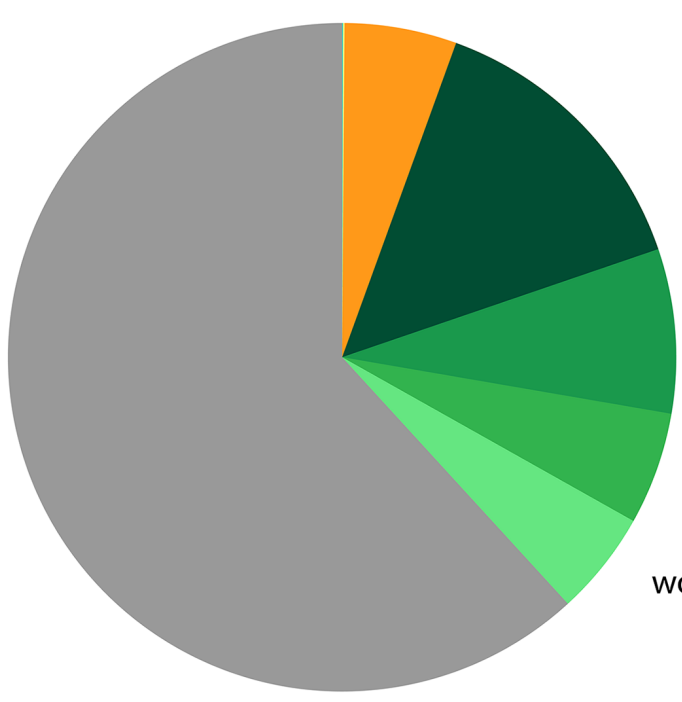

FIGURE 4 | BMI variance explained by final regression model in men and women. The pie charts show the squared part correlations of all variables of the final BMI model in the TFEQ-plus cohort $(n=192)$. All variables with significant correlation to BMI were included. As the directions of the effect of BAS and BIS differed between men and women, separate models comprising
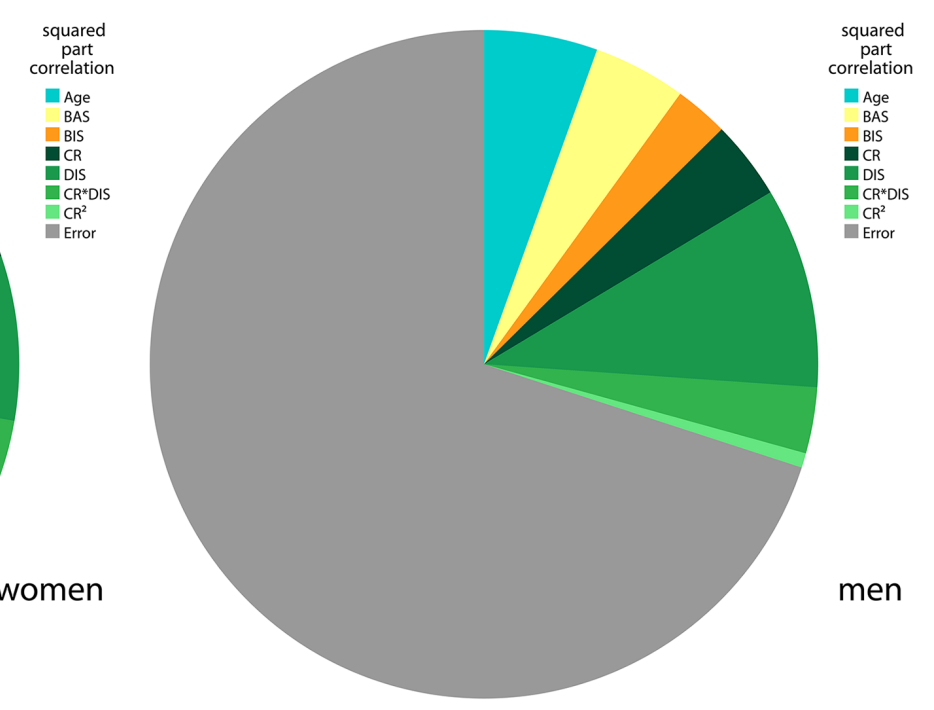

the same variables were computed. $R^{2}$ for women $(n=82)=0.382 . R^{2}$ for men $(n=110)=0.300$. CR, TFEQ cognitive restraint score; DIS, TFEQ disinhibition score; BAS, Behavioral Activation System total score; BIS, Behavioral Inhibition System total score; TFEQ, Three-Factor Eating Questionnaire.

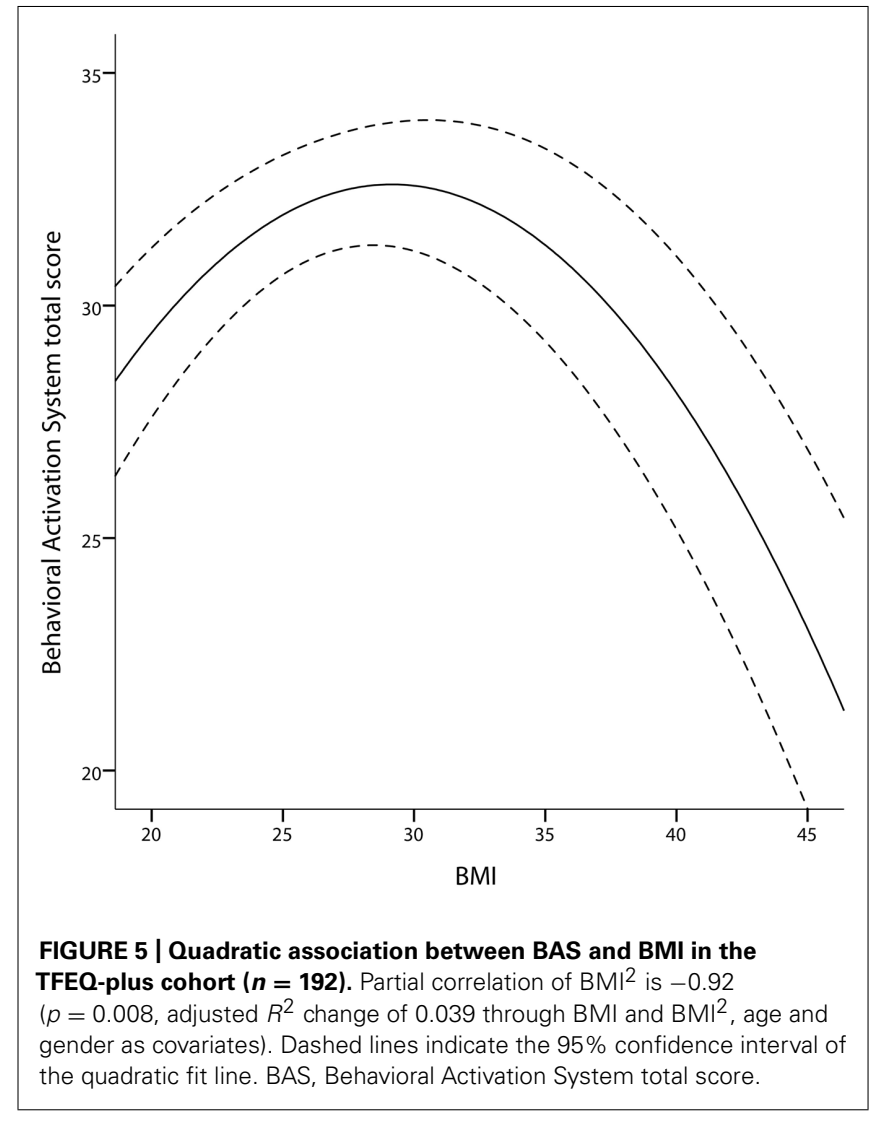

individuals presumably do not adequately adapt their dietary restraint. On the contrary, the model indicates that attempts to restrict food intake decrease (reflected in lower levels of cognitive restraint) with stronger disinhibited eating. Eating behavior seems to be more and more dominated by an uncontrolled eating style, driven by, for example, external eating signals or habitual food intake.

\section{GENDER-SPECIFIC RELATIONSHIPS BETWEEN BIS/BAS AND BMI}

The aforementioned model for BMI based on eating behavior was extended to incorporate personality factors not inherently related to food context but potentially influencing body weight. Both BIS and $B A S$ explained part of BMI variance independently of eating behavior $(\sim 6 \%)$, whereby they inversely accounted for BMI variance in men and women. Both scales were positively associated with BMI in women, but negatively in men.

\section{BAS RESPONSIVENESS AND BMI}

Studies already showed that reward responsiveness is positively related to body weight status and eating habits contributing to weight gain in women (Davis and Woodside, 2002; Davis et al., 2004; Franken and Muris, 2005; Loxton and Dawe, 2006). Women report more food cravings than men, indicating heightened motivation for hedonic eating (Lafay et al., 2001; Cepeda-Benito et al., 2003; Meule et al., 2012). Moreover, several studies have shown that women are highly susceptible to the sociocultural pressure resulting from the "lean ideal" portrayed by the media, leading to attempts to lose weight and be slim (Polivy and Herman, 2004; Dittmar, 2005; Mask and Blanchard, 2011; Yean et al., 2013). As a consequence food restriction and avoidance behavior might boost initial vulnerability to and incentive saliency of highly palatable "forbidden" food. In males, drive for a lean body has been shown to be lower (e.g., Cohane and Pope, 2001; Grogan and Richards, 2002; Yean et al., 2013). Their individual motivational value of food might thus be less environmentally influenced. 
Table 4 | Pearson correlations.

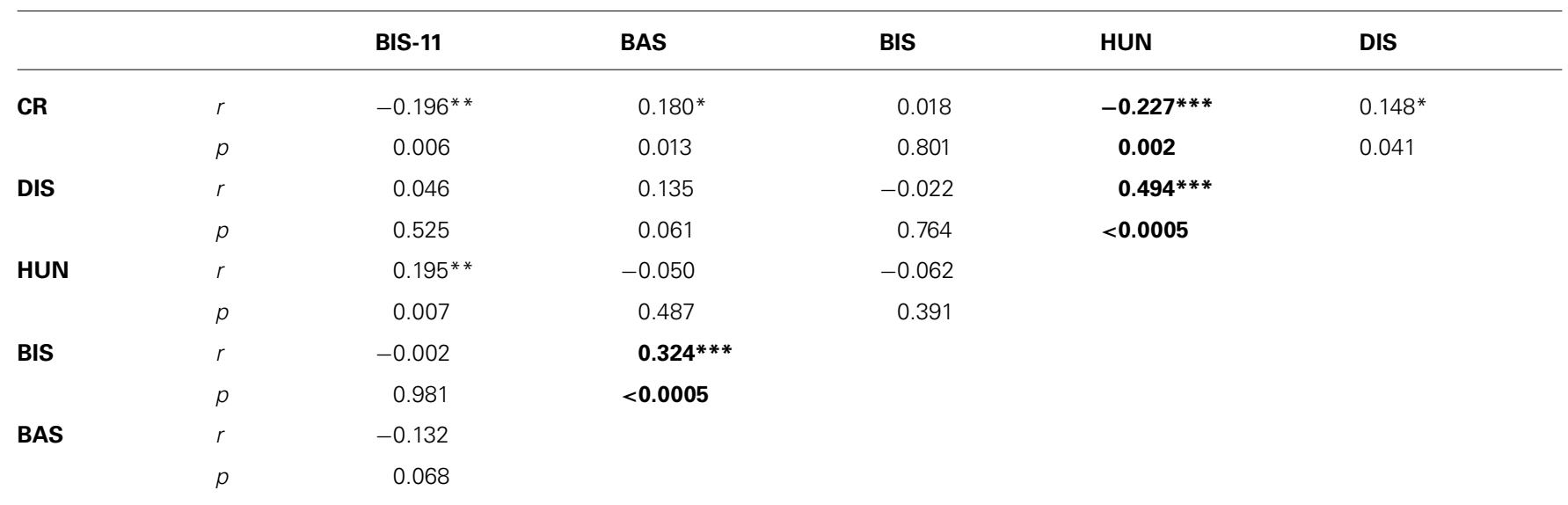

${ }^{*} p<0.05,{ }^{*} p<0.01,{ }^{* *} p<0.0033$.

Pearson correlations between all assessed questionnaire scores in the TFEQ-plus cohort ( $n=192)$. p-values $<0.0033$ (***, bold) are considered as significant after Bonferroni correction for multiple comparison. Noticeable are the associations of CR with HUN (negative), DIS with HUN (positive), and BAS with BIS (positive) as well as the trend toward the correlation of CR and BIS-11 (negative). CR, TFEQ cognitive restraint Score; DIS, TFEQ disinhibition Score; HUN, TFEQ hunger score;

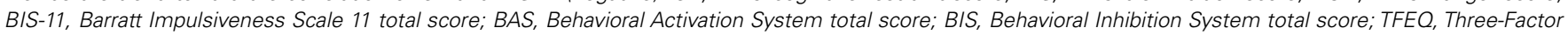
Eating Questionnaire.

For men, reward associated with novelty and excitement might be particularly reinforcing. Studies reported a higher risk for excitement-related addiction like pathological gambling (see van den Bos et al., 2013a for review), alcohol and cannabis (Wagner and Anthony, 2007; NSDUH, 2012; EMCDAA, 2013) or exercise dependence (Crossman et al., 1987; Pierce et al., 1997; Weik and Hale, 2009) in men.

\section{BIS RESPONSIVENESS AND BMI}

Emotional eating, which is related to punishment sensitivity (Gray, $1970,1982,1987$ ), serves as a way to compensate perceived punishment/negative affect in women (van Strien et al., 1986, 2013; Geliebter and Aversa, 2003; Nolan, 2012). Therefore obesity in women with high BIS responsiveness might be related to compensational eating. Men generally show a lower sensitivity to punishment (Cross et al., 2011) as well as stronger emotional and cognitive control over immediate emotional events (especially punishments; van den Bos et al., 2013b), presumably reducing their need for compensation of negative emotionality. Further, there is no clear-cut link between negative emotional eating and BMI in men (Macht et al., 2002; Geliebter and Aversa, 2003; Nolan, 2012), and, in contrast to women, food craving has been associated with positive mood states (Lafay et al., 2001). In contrast to women $B I S$ responsiveness in men might reflect differences in risk taking behavior. Koritzky et al. (2012) showed that particularly overweight and obese in comparison to lean men decided more often for high immediate reward despite long-term losses. Accordingly, they might more easily ignore long-term consequences of overeating, such as weight gain, because of low sensitivity to related punishment.

Although the BIS and BAS scales are assumed to be orthogonal (Gray, 1982, 1987), we found a correlation between the two measures. As BMI moderated the relationship between BIS and $B A S$ in women, we assume that differences in body weight status accounted for this effect in our sample.

\section{INVERTED U-SHAPED RELATIONSHIP BETWEEN BMI AND BAS}

We corroborated the inverted U-shaped relationship between sensitivity to reward and BMI demonstrated by Davis and Fox (2008) using the BAS scale. Following Davis and Fox (2008), subjects with a high BMI in the non-obese range are supposed to face stronger food cravings and appetitive drive, resulting in enhanced hedonic eating, weight gain, and possibly overweight. Davis and Fox (2008) assumed that these individuals detect rewarding stimuli like palatable food more easily and more likely approach them. The inverse relationship between $\mathrm{BMI}$ and $B A S$ in the obese range of the BMI is supposed to reflect reward deficiency resulting from hypoDA functioning in obese individuals (Wang et al., 2001; Volkow et al., 2008; de Weijer et al., 2011). Compensatory hedonic eating probably compensate for this deficiency.

\section{RELATIONSHIP BETWEEN SELF-REPORTED IMPULSIVITY AND BMI}

The contribution of self-reported impulsivity on body weight remains vague. Impulsivity did not explain BMI variance in our dataset. Contradictory results regarding the relationship with BMI have been reported previously (Nolan, 2012; van Koningsbruggen et al., 2013). In general, none of the subscales seem to be consistently related to overeating or BMI (Meule, 2013). However, we observed a trend for a negative correlation between BIS-11 and cognitive restraint. This indicates an indirect influence of impulsivity on body weight status via eating behavior, which is in line with previous findings (Leitch et al., 2013).

\section{STUDY LIMITATIONS AND FUTURE DIRECTIONS}

This study is based on analyses of self-reported measures, i.e., mentally represented, explicitly accessible information. We have not considered automatic processes (i.e., eating habits) like implicit food attitudes (e.g., Papies et al., 2009; Goldstein et al., 2014) or implicit liking/wanting (e.g., Berridge and Robinson, 2003; Finlayson et al., 2008), which should be regarded in future studies. 
Furthermore, impulsivity is a multifaceted construct (e.g., Patton etal., 1995; Whiteside and Lynam, 2001). According to insufficient validity of the factor structure of the BIS-11 in German (Preuss et al., 2008) we restricted our analysis to the BIS-11 total score. Another impulsivity scale, the UPPS Impulsive Behavior Scale (Whiteside and Lynam, 2001), is recommended as an additional self-report measure of impulsivity. This scale is associated with obesity (Mobbs et al., 2010), but probably measures aspects of impulsivity that are not covered by BIS-11 (Meule, 2013).

Moreover, cognitive restraint has been proposed to be subdivided into a rigid and flexible component (Westenhoefer, 1991; Westenhoefer et al., 1999). For reasons of construct validity, the cognitive restraint scale has been expanded by several further items (Westenhoefer et al., 1999). We recommend assessment of these items, because subscaling allows a more detailed analysis of cognitive restraint's influence on body weight.

Finally, BMI, although a common way to assess obesity, is a rather course measure. It relates body weight to body height without taking actual body composition into account. As it does not measure body fat directly, erroneous evaluation of body weight status with respect to obesity can occur (Rothman, 2008). Addressing this limitation, we recommend consideration of additional measures like waist/hip ratio or concentration of adipokines like leptin (Badman and Flier, 2005).

\section{SUMMARY}

This study demonstrates that responsiveness to the behavioral activation and behavioral inhibition system explains differences in $\mathrm{BMI}$ independently of eating behavior. Interestingly the relationships of BMI to BIS and BAS depend on gender, with opposing directions in men and women. Therefore, specified for men and women, BIS/BAS responsiveness should be considered in the treatment of obesity. Further, our study contributes to a better understanding of the complex relationships between eating behavior and body weight status. We showed that cognitive restraint and BMI are non-linearly associated (inverted U-shaped relationship). Importantly, this relationship is moderated by the level of disinhibition.

\section{ACKNOWLEDGMENTS}

We would like to thank Kieran Austin, Andreas Below, Dana Ersing, Karolin Gohlke, Stefan Kabisch, Jonas Klinkenberg, Christina Lell, Katja Macher, David Mathar, Lara Müller-Wieland, Jane Neumann, Haiko Schlögl, and Anke Theilemann for helping to establish the data collection from which the current data were drawn. We also would like to thank Jane Neumann, Nora Mehl, Isabel Garcia-Garcia, David Mathar, and Jakob Simmank, who provided valuable feedback on an earlier version of this manuscript.

The work of Martin Federbusch, Claudia Grellmann, Arno Villringer, and Annette Horstmann is supported by the IFB Adiposity Diseases, Federal Ministry of Education and Research (BMBF), Germany, FKZ: 01E01001 (http://www.bmbf.de). The work of Arno Villringer and Annette Horstmann is funded by the German Research Foundation (DFG; http://www.dfg.de), within the framework of the Collaborative Research Center 1052 "Obesity Mechanisms." Anja Dietrich is funded by a research grant from the Konrad Adenauer Foundation (www.kas.de).

\section{REFERENCES}

Ahima, R. S. (2008). Revisiting leptin's role in obesity and weight loss. J. Clin. Invest. 118, 2380-2383. doi: 10.1172/JCI36284.2380

Arnett, J. (1992). Reckless behavior in adolescence: a developmental perspective. Dev. Rev. 12, 339-373. doi: 10.1016/0273-2297(92)90013-R

Badman, M. K., and Flier, J. S. (2005). The gut and energy balance: visceral allies in the obesity wars. Science 307, 1909-1914. doi: 10.1126/science. 1109951

Batterink, L., Yokum, S., and Stice, E. (2010). Body mass correlates inversely with inhibitory control in response to food among adolescent girls: an fMRI study. Neuroimage 52, 1696-1703. doi: 10.1016/j.neuroimage.2010.05.059

Beaver, J. D., Lawrence, A. D., van Ditzhuijzen, J., Davis, M. H., Woods, A., and Calder, A. J. (2006). Individual differences in reward drive predict neural responses to images of food. J. Neurosci. 26, 5160-5166. doi: 10.1523/JNEUROSCI.035006.2006

Bellisle, F., Clément, K., Le Barzic, M., Le Gall, A., Guy-Grand, B., and Basdevant, A. (2004). The Eating Inventory and body adiposity from leanness to massive obesity: a study of 2509 adults. Obes. Res. 12, 2023-2030. doi: 10.1038/oby.2004.253

Berridge, K. C., and Robinson, T. E. (2003). Parsing reward. Trends Neurosci. 26, 507-513. doi: 10.1016/S0166-2236(03)00233-239

Bond, M. J., McDowell, A. J., and Wilkinson, J. Y. (2001). The measurement of dietary restraint, disinhibition and hunger: an examination of the factor structure of the Three Factor Eating Questionnaire (TFEQ). Int. J. Obes. Relat. Metab. Disord. 25, 900-906. doi: 10.1038/sj.ijo.0801611

Boschi, V., Iorio, D., Margiotta, N., D’Orsi, P., and Falconi, C. (2001). The threefactor eating questionnaire in the evaluation of eating behaviour in subjects seeking participation in a dietotherapy programme. Ann. Nutr. Metab. 45, 72-77. doi: 10.1159/000046709

Braet, C., Claus, L., Verbeken, S., and Van Vlierberghe, L. (2007). Impulsivity in overweight children. Eur. Child Adolesc. Psychiatry 16, 473-483. doi: 10.1007/s00787-007-0623-622

Brogan, A., Hevey, D., O’Callaghan, G., Yoder, R., and O’Shea, D. (2011). Impaired decision making among morbidly obese adults. J. Psychosom. Res. 70, 189-196. doi: 10.1016/j.jpsychores.2010.07.012

Brogan, A., Hevey, D., and Pignatti, R. (2010). Anorexia, bulimia, and obesity: shared decision making deficits on the Iowa Gambling Task (IGT). J. Int. Neuropsychol. Soc. 16, 711-715. doi: 10.1017/S135561 7710000354

Bryant, E. J., King, N. A., and Blundell, J. E. (2008). Disinhibition: its effects on appetite and weight regulation. Obes. Rev. 9, 409-419. doi: 10.1111/j.1467789X.2007.00426.x

Burgess, L. H., and Handa, R. J. (1992). Chronic estrogen-induced alterations in adrenocorticotropin and corticosterone secretion, and glucocorticoid receptor-mediated functions in female rats. Endocrinology 131, 1261-1269. doi: 10.1210/en.131.3.1261

Byrnes, J. P., Miller, D. C., and Schafer, W. D. (1999). Gender differences in risk taking: a meta-analysis. Psychol. Bull. 125, 367-383. doi: 10.1037/00332909.125.3.367

Cappelleri, J. C., Bushmakin, A. G., Gerber, R. A., Leidy, N. K., Sexton, C. C., Lowe, M. R., etal. (2009). Psychometric analysis of the Three-Factor Eating Questionnaire-R21: results from a large diverse sample of obese and non-obese participants. Int. J. Obes. (Lond.) 33, 611-620. doi: 10.1038/ijo. 2009.74

Carroll, M. E., Lynch, W. J., Roth, M. E., Morgan, A. D., and Cosgrove, K. P. (2004). Sex and estrogen influence drug abuse. Trends Pharmacol. Sci. 25, 273-279. doi: 10.1016/j.tips.2004.03.011

Carver, C. S., and White, T. L. (1994). Behavioral inhibition, behavioral activation, and affective responses to impending reward and punishment: The BIS/BAS Scales. J. Pers. Soc. Psychol. 67, 319-333. doi: 10.1037/0022-3514.67. 2.319

Cepeda-Benito, A., Fernandez, M. C., and Moreno, S. (2003). Relationship of gender and eating disorder symptoms to reported cravings for food: construct validation of state and trait craving questionnaires in Spanish. Appetite 40, 47-54. doi: 10.1016/S0195-6663(02)00145-149

Chalmers, D. K., Bowyer, C. A., and Olenick, N. L. (1990). Problem drinking and obesity: a comparison in personality patterns and life-style. Int. J. Addict. 25, 803-817. 
Cohane, G. H., and Pope, H. G. (2001). Body image in boys: a review of the literature. Int. J. Eat. Disord. 29, 373-379. doi: 10.1002/eat.1033

Cross, C. P., Copping, L. T., and Campbell, A. (2011). Sex differences in impulsivity: a meta-analysis. Psychol. Bull. 137, 97-130. doi: 10.1037/a0021591

Crossman, J., Jamieson, J., and Henderson, L. (1987). Responses of competitive athletes to layoffs in training: exercise addiction or psychological relief? J. Sport Behav. 10, 28-38.

Dalle Grave, R., Calugi, S., Corica, F., Di Domizio, S., and Marchesini, G. (2009). Psychological variables associated with weight loss in obese patients seeking treatment at medical centers. J. Am. Diet. Assoc. 109, 2010-2016. doi: 10.1016/j.jada.2009.09.011

Davis, C. (2013). A narrative review of binge eating and addictive behaviors: shared associations with seasonality and personality factors. Front. Psychiatry 4:183. doi: $10.3389 /$ fpsyt.2013.00183

Davis, C., and Fox, J. (2008). Sensitivity to reward and body mass index (BMI): evidence for a non-linear relationship. Appetite 50, 43-49. doi 10.1016/j.appet.2007.05.007

Davis, C., Patte, K., Levitan, R., Reid, C., Tweed, S., and Curtis, C. (2007). From motivation to behaviour: a model of reward sensitivity, overeating, and food preferences in the risk profile for obesity. Appetite 48, 12-19. doi: 10.1016/j.appet.2006.05.016

Davis, C., Strachan, S., and Berkson, M. (2004). Sensitivity to reward: implications for overeating and overweight. Appetite 42, 131-138. doi: 10.1016/j.appet.2003.07.004

Davis, C., and Woodside, D. B. (2002). Sensitivity to the rewarding effects of food and exercise in the eating disorders. Compr. Psychiatry 43, 189-194. doi: 10.1053/comp.2002.32356

de Lauzon-Guillain, B., Basdevant, A., Romon, M., Karlsson, J., Borys, J.-M., Charles, M. A., et al. (2006). Is restrained eating a risk factor for weight gain in a general population? Am. J. Clin. Nutr. 83, 132-138. doi: 10.1186/2191-219X-1-37

de Weijer, B. A., van de Giessen, E., van Amelsvoort, T. A., Boot, E., Braak, B., Janssen, I. M., et al. (2011). Lower striatal dopamine D2/3 receptor availability in obese compared with non-obese subjects. EJNMMI Res. 1, 37. doi: 10.1186/2191 219X-1-37

Dina, C., Meyre, D., Gallina, S., Durand, E., Körner, A., Jacobson, P., et al. (2007). Variation in FTO contributes to childhood obesity and severe adult obesity. Nat Genet. 39, 724-726. doi: 10.1038/ng2048

Dittmar, H. (2005). Introduction to the special issue: body image-vulnerability factors and processes linking sociocultural pressures and body dissatisfaction. $J$. Soc. Clin. Psychol. 24, 1081-1087. doi: 10.1521/jscp.2005.24.8.1081

Dykes, J., Brunner, E. J., Martikainen, P. T., and Wardle, J. (2004). Socioeconomic gradient in body size and obesity among women: the role of dietary restraint, disinhibition and hunger in the Whitehall II study. Int. J. Obes. Relat. Metab. Disord. 28, 262-268. doi: 10.1038/sj.ijo.0802523

Elfhag, K., and Morey, L. C. (2008). Personality traits and eating behavior in the obese: poor self-control in emotional and external eating but personality assets in restrained eating. Eat. Behav. 9, 285-293. doi: 10.1016/j.eatbeh.2007. 10.003

EMCDAA. (2013). European Drug Report 2013: Trends and Developments. Available at: http://www.emcdda.europa.eu/publications/edr/trends-developments/2013

Evans, S. M., Haney, M., and Foltin, R. W. (2002). The effects of smoked cocaine during the follicular and luteal phases of the menstrual cycle in women. Psychopharmacology (Berl.) 159, 397-406. doi: 10.1007/s00213-001-0944-947

Faith, M. S., Flint, J., Fairburn, C. G., Goodwin, G. M., and Allison, D. B. (2001). Gender differences in the relationship between personality dimensions and relative body weight. Obes. Res. 9, 647-650. doi: 10.1038/oby.2001.86

Farooqi, I. S., Bullmore, E., Keogh, J., Gillard, J., O’Rahilly, S., and Fletcher, P. C. (2007). Leptin regulates striatal regions and human eating behavior. Science 317, 1355. doi: 10.1126/science. 1144599

Fattore, L., Altea, S., and Fratta, W. (2008). Sex differences in drug addiction: a review of animal and human studies. Womens Health (Lond. Engl.) 4, 51-65. doi: 10.2217/17455057.4.1.51

Fattore, L., Fadda, P., and Fratta, W. (2009). Sex differences in the self-administration of cannabinoids and other drugs of abuse. Psychoneuroendocrinology 34(Suppl. 1), S227-S236. doi: 10.1016/j.psyneuen.2009.08.008

Finlayson, G., King, N., and Blundell, J. (2008). The role of implicit wanting in relation to explicit liking and wanting for food: implications for appetite control. Appetite 50, 120-127. doi: 10.1016/j.appet.2007.06.007
Foster, G. D., Wadden, T. A., Swain, R. M., Stunkard, A. J., Platte, P., and Vogt, R. A. (1998). The eating inventory in obese women: clinical correlates and relationship to weight loss. Int. J. Obes. Relat. Metab. Disord. 22, 778-785. doi: 10.1038/sj.ijo.0800659

Franken, I. H., and Muris, P. (2005). Individual differences in reward sensitivity are related to food craving and relative body weight in healthy women. Appetite 45, 198-201. doi: 10.1016/j.appet.2005.04.004

Frayling, T. M., Timpson, N. J., Weedon, M. N., Zeggini, E., Freathy, R. M., Lindgren, C. M., et al. (2007). A common variant in the FTO gene is associated with body mass index and predisposes to childhood and adult obesity. Science 316, 889-894. doi: $10.1126 /$ science. 1141634

Geliebter, A., and Aversa, A. (2003). Emotional eating in overweight, normal weight, and underweight individuals. Eat. Behav. 3, 341-347. doi: 10.1016/S1471-0153(02)00100-109

Goldstein, S. P., Forman, E. M., Meiran, N., Herbert, J. D., Juarascio, A. S., and Butryn, M. L. (2014). The discrepancy between implicit and explicit attitudes in predicting disinhibited eating. Eat. Behav. 15, 164-170. doi: 10.1016/j.eatbeh.2013.10.021

Gray, J. (1970). The psychophysiological basis of introversion-extraversion. Behav. Res. Ther. 8, 249-266. doi: 10.1016/0005-7967(70)90069-90060

Gray, J. A. (1982). Neuropsychological Theory of Anxiety. New York: Oxford University Press.

Gray, J. A. (1987). The Physiology of Fear and Stress. Camebridge: Camebridge University Press.

Gray, J. A., and McNaughton, N. (ed.). (2000). The Neuropsychology of Anxiety, 2nd Edn. Oxford: Oxford University Press.

Grogan, S., and Richards, H. (2002). Body image: focus groups with boys and men. Men Masc. 4, 219-232. doi: 10.1177/1097184X02004003001

Guerrieri, R., Nederkoorn, C., and Jansen, A. (2007). How impulsiveness and variety influence food intake in a sample of healthy women. Appetite 48, 119-122. doi: 10.1016/j.appet.2006.06.004

Guerrieri, R., Nederkoorn, C., and Jansen, A. (2008). The effect of an impulsive personality on overeating and obesity: current state of affairs. Psychol. Top. 17, 265-286.

Handa, R. J., Burgess, L. H., Kerr, J. E., and O’Keefe, J. A. (1994). Gonadal steroid hormone receptors and sex differences in the hypothalamo-pituitary-adrenal axis. Horm. Behav. 28, 464-476. doi: 10.1006/hbeh.1994.1044

Harrison, A., O’Brien, N., Lopez, C., and Treasure, J. (2010). Sensitivity to reward and punishment in eating disorders. Psychiatry Res. 177, 1-11. doi: 10.1016/j.psychres.2009.06.010

Harrison, A., Treasure, J., and Smillie, L. D. (2011). Approach and avoidance motivation in eating disorders. Psychiatry Res. 188, 396-401. doi: 10.1016/j.psychres.2011.04.022

Hayes, A. (2013). Introduction to Mediation, Moderation, and Conditional Process Analysis. New York: Guilford Press.

Hays, N. P., Bathalon, G. P., McCrory, M. A., Roubenoff, R., Lipman, R., and Roberts, S. B. (2002). Eating behavior correlates of adult weight gain and obesity in healthy women aged 55-65 y. Am. J. Clin. Nutr. 75, 476-483. doi: 10.1176/appi.ajp.158.2.308

Horstmann, A., Busse, F. P., Mathar, D., Müller, K., Lepsien, J., Schlögl, H., et al. (2011). Obesity-related differences between women and men in brain structure and goal-directed behavior. Front. Hum. Neurosci. 5:58. doi: 10.3389/fnhum.2011.00058

Jorm, A. F., Christensen, H., Henderson, A. S., Jacomb, P. A., Korten, P. A., and Rodgers, B. (1999). Using the BIS/BAS scales to measure behavioural inhibition and behavioural activation: factor structure, validity and norms in a large community sample. Pers. Individ. Dif. 26, 49-58. doi: 10.1016/S0191-8869(98)00143-143 Jubbin, J. J., and Rajesh, I. (2012). Behavioral therapy for management of obesity. Indian J. Endocrinol. Metab. 16, 28-32. doi: 10.4103/2230-8210.91180

Kaasinen, V., Någren, K., Hietala, J., Farde, L., and Rinne, J. O. (2001). Sex differences in extrastriatal dopamine $\mathrm{d}_{2}$-like receptors in the human brain. Am. J. Psychiatry 158, 308-311. doi: 10.1176/appi.ajp.158.2.308

Karlsson, J., Hallgren, P., Kral, J., Lindroos, A. K., Sjöström, L., and Sullivan, M. (1994). Predictors and effects of long-term dieting on mental well-being and weight loss in obese women. Appetite 23, 15-26. doi: 10.1006/appe.1994.1031

Keel, P. K., Baxter, M. G., Heatherton, T. F., and Joiner, T. E. (2007). A 20-year longitudinal study of body weight, dieting, and eating disorder symptoms. J. Abnorm. Psychol. 116, 422-432. doi: 10.1037/0021-843X.116.2.422 
Klok, M. D., Jakobsdottir, S., and Drent, M. L. (2007). The role of leptin and ghrelin in the regulation of food intake and body weight in humans: a review. Obes. Rev. 8, 21-34. doi: 10.1111/j.1467-789X.2006.00270.x

Koritzky, G., Yechiam, E., Bukay, I., and Milman, U. (2012). Obesity and risk taking. a male phenomenon. Appetite 59, 289-297. doi: 10.1016/j.appet.2012.05.020

Lafay, L., Thomas, F., Mennen, L., Charles, M. A., Eschwege, E., Borys, J. M., et al. (2001). Gender differences in the relation between food cravings and mood in an adult community: results from the fleurbaix laventie ville santé study. Int. J. Eat. Disord. 29, 195-204. doi: 10.1002/1098-108X(200103)29:2<195::AIDEAT1009>3.0.CO;2-N

Le, D. S. N., Pannacciulli, N., Chen, K., Salbe, A. D., Del Parigi, A., Hill, J. O., et al. (2007). Less activation in the left dorsolateral prefrontal cortex in the reanalysis of the response to a meal in obese than in lean women and its association with successful weight loss. Am. J. Clin. Nutr. 86, 573-579.

Le, D. S. N. T., Pannacciulli, N., Chen, K., Del Parigi, A., Salbe, A. D., Reiman, E. M., et al. (2006). Less activation of the left dorsolateral prefrontal cortex in response to a meal: a feature of obesity. Am. J. Clin. Nutr. 84, 725-731. doi: 10.1016/j.appet.2012.05.027

Leitch, M. A., Morgan, M. J., and Yeomans, M. R. (2013). Different subtypes of impulsivity differentiate uncontrolled eating and dietary restraint. Appetite 69 , 54-63. doi: 10.1016/j.appet.2013.05.007

Lesdéma, A., Fromentin, G., Daudin, J.-J., Arlotti, A., Vinoy, S., Tome, D., et al. (2012). Characterization of the Three-Factor Eating Questionnaire scores of a young French cohort. Appetite 59, 385-390. doi: 10.1016/j.appet.2012. 05.027

Li, K.-K., Concepcion, R. Y., Lee, H., Cardinal, B. J., Ebbeck, V., Woekel, E., et al. (2012). An examination of sex differences in relation to the eating habits and nutrient intakes of university students. J. Nutr. Educ. Behav. 44, 246-250. doi: 10.1016/j.jneb.2010.10.002

Lluch, A., Herbeth, B., Mejean, L., and Siest, G. (2000). Dietary intakes, eating style and overweight in the Stanislas Family Study. Int. J. Obes. Relat. Metab. Disord. 24, 1493-1499. doi: 10.1038/sj.ijo.0801425

Loxton, N. J., and Dawe, S. (2006). Reward and punishment sensitivity in dysfunctional eating and hazardous drinking women: associations with family risk. Appetite 47, 361-371. doi: 10.1016/j.appet.2006.05.014

Lynch, W. J., Roth, M. E., and Carroll, M. E. (2002). Biological basis of sex differences in drug abuse: preclinical and clinical studies. Psychopharmacology (Berl.) 164 121-137. doi: 10.1007/s00213-002-1183-1182

Macht, M., Roth, S., and Ellgring, H. (2002). Chocolate eating in healthy men during experimentally induced sadness and joy. Appetite 39, 147-158. doi: 10.1006/appe.2002.0499

Mask, L., and Blanchard, C. M. (2011). The effects of "thin ideal" media on women's body image concerns and eating-related intentions: the beneficial role of an autonomous regulation of eating behaviors. Body Image 8, 357-365. doi: 10.1016/j.bodyim.2011.06.003

Matton, A., Goossens, L., Braet, C., and Vervaet, M. (2013). Punishment and reward sensitivity: are naturally occurring clusters in these traits related to eating and weight problems in adolescents? Eur. Eat. Disord. Rev. 21, 184-194. doi: $10.1002 /$ erv. 2226

Meule, A. (2013). Impulsivity and overeating: a closer look at the subscales of the Barratt Impulsiveness Scale. Front. Psychol. 4:177. doi: 10.3389/fpsyg.2013. 00177

Meule, A., Lutz, A., Vögele, C., and Kübler, A. (2012). Food cravings discriminate differentially between successful and unsuccessful dieters and non-dieters. Validation of the Food Cravings Questionnaires in German. Appetite 58, 88-97. doi: 10.1016/j.appet.2011.09.010

Mobbs, O., Crépin, C., Thiéry, C., Golay, A., and Van der Linden, M. (2010). Obesity and the four facets of impulsivity. Patient Educ. Couns. 79, 372-377. doi: 10.1016/j.pec.2010.03.003

Moeller, F. G., Barratt, E. S., Dougherty, D. M., Schmitz, J. M., and Swann, A. C. (2001). Psychiatric aspects of impulsivity. Am. J. Psychiatry 158, 1783-1793. doi: 10.1176/appi.ajp.158.11.1783

Nederkoorn, C., Braet, C., Van Eijs, Y., Tanghe, A., and Jansen, A. (2006a). Why obese children cannot resist food: the role of impulsivity. Eat. Behav. 7, 315-322. doi: 10.1016/j.eatbeh.2005.11.005

Nederkoorn, C., Smulders, F. T. Y., Havermans, R. C., Roefs, A., and Jansen, A. (2006b). Impulsivity in obese women. Appetite 47, 253-256. doi: 10.1016/j.appet.2006.05.008
Nolan, J. (2012). Association between impulsiveness and pleasantness ratings for food and drugs. Appetite 59, e43. doi: 10.1016/j.appet.2012.05.003

NSDUH. (2012). National Survey on Drug Use \& Health: Results from the 2012. Available at: http://www.samhsa.gov/data/NSDUH/2k12MH_FindingsandDetTables/ 2K12MHF/NSDUHmhfr2012.htm

Page, K. A., Seo, D., Belfort-DeAguiar, R., Lacadie, C., Dzuira, J., Naik, S., et al. (2011). Circulating glucose levels modulate neural control of desire for highcalorie foods in humans. J. Clin. Invest. 121, 4161-4169. doi: 10.1172/JCI57873

Papies, E. K., Stroebe, W., and Aarts, H. (2009). Who likes it more? Restrained eaters' implicit attitudes towards food. Appetite 53, 279-287. doi: 10.1016/j.appet.2009.07.001

Patchev, V. K., Hayashi, S., Orikasa, C., and Almeida, O. F. (1995). Implications of estrogen-dependent brain organization for gender differences in hypothalamopituitary-adrenal regulation. FASEB J. 9, 419-423.

Patton, J. H., Stanford, M. S., and Barratt, E. S. (1995). Factor structure of the Barratt impulsiveness scale. J. Clin. Psychol. 51, 768-774. doi: 10.1002/10974679(199511)51:6<768::AID-JCLP2270510607>3.0.CO;2-1

Pekkarinen, T., Takala, I., and Mustajoki, P. (1996). Two year maintenance of weight loss after a VLCD and behavioural therapy for obesity: correlation to the scores of questionnaires measuring eating behaviour. Int. J. Obes. Relat. Metab. Disord. 20, 332-337.

Pierce, E. F., Rohaly, K. A., and Fritchley, B. (1997). Sex differences on exercise dependence for men and women in a marathon road race. Percept. Mot. Skills 84, 991-994. doi: 10.2466/pms.1997.84.3.991

Pignatti, R., Bertella, L., Albani, G., Mauro, A., Molinari, E., and Semenza, C. (2006). Decision-making in obesity: a study using the Gambling task. Eat. Weight Disord. 11, 126-132. doi: 10.1007/BF03327557

Polivy, J., and Herman, C. P. (2004). Sociocultural idealization of thin female body shapes: an introduction to the special issue on body image and eating disorders. J. Soc. Clin. Psychol. 23, 1-6. doi: 10.1521/jscp.23.1.1.26986

Preuss, U. W., Rujescu, D., Giegling, I., Watzke, S., Koller, G., Zetzsche, T., et al. (2008). Psychometric evaluation of the German version of the Barratt Impulsiveness Scale. Nervenarzt 79, 305-319. doi: 10.1007/s00115-007-23 60-2367

Provencher, V., Drapeau, V., Tremblay, A., Després, J.-P., Bouchard, C., and Lemieux, S. (2004). Eating behaviours, dietary profile and body composition according to dieting history in men and women of the Québec Family Study. Br. J. Nutr. 91, 997-1004. doi: 10.1079/BJN20041115

Pudel, V., and Westenhoefer, J. (1989). Fragebogen Zum Essverhalten (FEV). Göttingen: Hogrefe.

Rasmussen, E. B., Lawyer, S. R., and Reilly, W. (2010). Percent body fat is related to delay and probability discounting for food in humans. Behav. Processes 83, 23-30. doi: 10.1016/j.beproc.2009.09.001

Rosenbaum, M., Sy, M., Pavlovich, K., Leibel, R. L., and Hirsch, J. (2008). Leptin reverses weight loss-induced changes in regional neural activity responses to visual food stimuli. J. Clin. Invest. 118, 2583-2591. doi: 10.1172/JCI35055

Rothman, K. J. (2008). BMI-related errors in the measurement of obesity. Int. J. Obes. (Lond.) 32, 56-59. doi: 10.1038/ijo.2008.87

Rydén, A., Sullivan, M., Torgerson, J. S., Karlsson, J., Lindroos, A.-K., and Taft, C. (2003). Severe obesity and personality: a comparative controlled study of personality traits. Int. J. Obes. Relat. Metab. Disord. 27, 1534-1540. doi: 10.1038 /sj.ijo.0802460

Savage, J. S., Hoffman, L., and Birch, L. L. (2009). Dieting, restraint, and disinhibition predict women's weight change over 6 y. Am. J. Clin. Nutr. 90, 33-40. doi: 10.3945/ajcn.2008.26558

Sofuoglu, M., Dudish-Poulsen, S., Nelson, D., Pentel, P. R., and Hatsukami, D. K. (1999). Sex and menstrual cycle differences in the subjective effects from smoked cocaine in humans. Exp. Clin. Psychopharmacol. 7, 274-283. doi: 10.1037/10641297.7.3.274

Strobel, A., Beauducel, A., Debener, S., and Brocke, B. (2001). Eine deutschsprachige Version des BIS/BAS-Fragebogens von Carver und White. Z. Differ. Diagn. Psychol. 22, 216-227. doi: 10.1024//0170-1789.22.3.216

Stunkard, A. J., and Messick, S. (1985). The three-factor eating questionnaire to measure dietary restraint, disinhibition and hunger. J. Psychosom. Res. 29, 71-83. doi: 10.1016/0022-3999(85)90010-90018

Tucker, L. A., and Bates, L. (2009). Restrained eating and risk of gaining weight and body fat in middle-aged women: a 3-year prospective study. Am. J. Health Promot. 23, 187-194. doi: 10.4278/ajhp.07061456 
van den Bos, R., Davies, W., Dellu-Hagedorn, F., Goudriaan, A. E., Granon, S., Homberg, J., et al. (2013a). Cross-species approaches to pathological gambling: a review targeting sex differences, adolescent vulnerability and ecological validity of research tools. Neurosci. Biobehav. Rev. 37, 2454-2471. doi: 10.1016/j.neubiorev.2013.07.005

van den Bos, R., Homberg, J., and de Visser, L. (2013b). A critical review of sex differences in decision-making tasks: focus on the Iowa Gambling Task. Behav. Brain Res. 238, 95-108. doi: 10.1016/j.bbr.2012.10.002

van Koningsbruggen, G. M., Stroebe, W., and Aarts, H. (2013). Successful restrained eating and trait impulsiveness. Appetite 60, 81-84. doi: 10.1016/j.appet.2012.09.016

van Strien, T., Cebolla, A., Etchemendy, E., Gutiérrez-Maldonado, J., Ferrer-García, M., Botella, C., etal. (2013). Emotional eating and food intake after sadness and joy. Appetite 66, 20-25. doi: 10.1016/j.appet.2013. 02.016

van Strien, T., Frijters, J. E. R., Bergers, G. P. A., and Defares, P. B. (1986). The Dutch Eating Behavior Questionnaire (DEBQ) for assessment of restrained, emotional and external eating behavior. Int. J. Eat. Disord. 5, 295-315. doi: 10.1002/1098 108X(198602)5:2<295::AID-EAT2260050209>3.0.CO;2-T

Volkow, N. D., Wang, G.-J., Fowler, J. S., and Telang, F. (2008). Overlapping neuronal circuits in addiction and obesity: evidence of systems pathology. Philos. Trans. $R$ Soc. Lond. B Biol. Sci. 363, 3191-3200. doi: 10.1098/rstb.2008.0107

Volkow, N. D., Wang, G.-J., Tomasi, D., and Baler, R. D. (2013). Obesity and addiction: neurobiological overlaps. Obes. Rev. 14, 2-18. doi: 10.1111/j.1467789X.2012.01031.x

Wagner, F. A., and Anthony, J. C. (2007). Male-female differences in the risk of progression from first use to dependence upon cannabis, cocaine, and alcohol. Drug Alcohol Depend. 86, 191-198. doi: 10.1016/j.drugalcdep.2006. 06.003

Wang, G. J., Volkow, N. D., Logan, J., Pappas, N. R., Wong, C. T., Zhu, W., et al. (2001). Brain dopamine and obesity. Lancet 357, 354-357. doi: 10.1016/S01406736(00)03643-6

Weik, M., and Hale, B. D. (2009). Contrasting gender differences on two measures of exercise dependence. Br. J. Sports Med. 43, 204-207. doi: 10.1136/bjsm.2007.045138

Weller, R. E., Cook, E. W., Avsar, K. B., and Cox, J. E. (2008). Obese women show greater delay discounting than healthy-weight women. Appetite 51, 563-569. doi: 10.1016/j.appet.2008.04.010

Westenhoefer, J. (1991). Dietary restraint and disinhibition: is restraint a homogeneous construct? Appetite 16, 45-55. doi: 10.1016/0195-6663(91) 90110-E

Westenhoefer, J., Pudel, V., and Maus, N. (1990). Some restrictions on dietary restraint. Appetite 14, 137-141. doi: 10.1016/0195-6663(90)90014-Y
Westenhoefer, J., Stunkard, A. J., and Pudel, V. (1999). Validation of the flexible and rigid control dimensions of dietary restraint. Int. J. Eat. Disord. 26, 53-64. doi: 10.1002/(SICI)1098-108X(199907)26

Westerterp-Plantenga, M. S., Kempen, K. P. G., and Saris, W. H. M. (1998). Determinants of weight maintenance in women after diet-induced weight reduction. Int. J. Obes. Relat. Metab. Disord. 22, 1-6. doi: 10.1038/sj.ijo.0800536

Weygandt, M., Mai, K., Dommes, E., Leupelt, V., Hackmack, K., Kahnt, T., et al. (2013). The role of neural impulse control mechanisms for dietary success in obesity. Neuroimage 83C, 669-678. doi: 10.1016/j.neuroimage.2013.07.028

Whiteside, S. P., and Lynam, D. R. (2001). The Five Factor Model and impulsivity: using a structural model of personality to understand impulsivity. Pers. Individ. Dif. 30, 669-689. doi: 10.1016/S0191-8869(00)00064-67

Wilksch, S. M., and Wade, T. D. (2009). An investigation of temperament endophenotype candidates for early emergence of the core cognitive component of eating disorders. Psychol. Med. 39, 811-821. doi: 10.1017/S0033291708004261

Williamson, D. A., Lawson, O. J., Brooks, E. R., Wozniak, P. J., Ryan, D. H., Bray, G. A., et al. (1995). Association of body mass with dietary restraint and disinhibition. Appetite 25, 31-41. doi: 10.1006/appe.1995.0039

Yean, C., Benau, E. M., Dakanalis, A., Hormes, J. M., Perone, J., and Timko, C. A. (2013). The relationship of sex and sexual orientation to self-esteem, body shape satisfaction, and eating disorder symptomatology. Front. Psychol. 4:887. doi: 10.3389/fpsyg.2013.00887

Young, E. A. (1995). The role of gonadal steroids in hypothalamic-pituitary-adrenal axis regulation. Crit. Rev. Neurobiol. 9, 371-381.

Conflict of Interest Statement: The authors declare that the research was conducted in the absence of any commercial or financial relationships that could be construed as a potential conflict of interest.

Received: 27 May 2014; accepted: 06 September 2014; published online: 20 October 2014.

Citation: Dietrich A, Federbusch M, Grellmann C, Villringer A and Horstmann A (2014) Body weight status, eating behavior, sensitivity to reward/punishment, and gender: relationships and interdependencies. Front. Psychol. 5:1073. doi: 10.3389/fpsyg.2014.01073

This article was submitted to Eating Behavior, a section of the journal Frontiers in Psychology.

Copyright (c) 2014 Dietrich, Federbusch, Grellmann, Villringer and Horstmann. This is an open-access article distributed under the terms of the Creative Commons Attribution License (CC BY). The use, distribution or reproduction in other forums is permitted, provided the original author(s) or licensor are credited and that the original publication in this journal is cited, in accordance with accepted academic practice. No use, distribution or reproduction is permitted which does not comply with these terms. 